\title{
PORTFÓLIO COMO INSTRUMENTO DE APRENDIZAGEM E AVALIAÇÃO
}

\author{
Marinês Pérsigo Morais Rigo, Melissa Mottin Ghisleni, Luísa Scheer Ely, Elisete Maria de \\ Freitas, Evandro Bratti, Eduardo Sehnem, Fernanda Scherer Adami \\ Centro Universitário UNIVATES \\ Lajeado, Rio Grande do Sul \\ E-mail: marinespmrigo@gmail.com, melmghisleni@gmail.com, luisa_ely@yahoo.com.br, elicauf@univates.br, \\ evandro.bratti@gmail.com, eduardosehnem@univates.br, fernandascherer@univates.br
}

\section{Jane Aparecida Garcia de Senna}

Secretaria de Municipal de Saúde de Lajeado

Lajeado, Rio Grande do Sul

E-mail: jane.senna1g@gmail.com

Resumo: O estudo objetivou verificar as percep̧̧ões dos estudantes a respeito do uso do portfólio como ferramenta de ensino-aprendizagem. Ao final da disciplina, 34 acadêmicos responderam a um questionário no intuito de obter informações quanto à importância do portfólio na promoção da aprendizagem. Dentre os estudantes, $94 \%$ avaliaram a metodologia como "boa" e "ótima", citando, como pontos relevantes, o incentivo à pesquisa e à reflexão. Apenas $6 \%$ consideraram o instrumento ruim e desgastante, no entanto, $50 \%$ destes afirmaram ser o incentivo à reflexão o ponto relevante da metodologia. A disponibilidade de tempo para seu desenvolvimento, planejamento para sua execução e a adequada pactuação entre docente e discentes foram considerados pontos importantes para o sucesso na sua aplicação.

Palavras-chave: avaliação do aprendizado. ferramenta de ensino-aprendizagem. incentivo à pesquisa. metodologias ativas. promoção da aprendizagem.

\section{PORTFOLIO AS A LEARNING AND ASSESSMENT TOOL}

Abstract: The study aimed to verify the student's perceptions about the portfolio use as a teaching and learning tool. At the end of the course, 34 students answered a questionnaire in order to obtain information on the importance of portfolio in learning promoting. Among the students, $94 \%$ rated the methodology as "good" and "great" citing as relevant points the encouragement of research and reflection. Only 6\% considered it a "bad" and "exhausting" instrument, however, 50\% of them said that encouraging reflection was the relevant point of the methodology. The time available for its development, planning for implementation and proper pact between teacher and students were considered important points for success in your application.

Keywords: learning assessment. teaching and learning tool. encouraging research. active methodologies. promoting learning.

Recebido em 12/01/2016. Publicado em 30/06/2016. 


\section{INTRODUÇÃO}

São muitos os debates em torno da necessidade de mudança no processo de formação profissional, principalmente na área da saúde, em virtude de o perfil destes profissionais demonstrar qualificação insuficiente para a implantação e o fortalecimento da integralidade da atenção à saúde (Gomes e outros, 2010). É preciso repensar os atuais pressupostos das práticas racionalistas e assistencialistas na formação dos profissionais de saúde. Isso porque, apesar dos evidentes avanços científicos e tecnológicos, não tem sido garantido o cuidado com a saúde dentro de uma relação de humanização, que contemple os princípios norteadores do cuidar de forma humana e carregada de vida, e que não represente apenas um ato mecânico, restrito à mera aplicação de técnicas (Rosito; Loterio, 2012).

Assim, está visível a necessidade de a formação do profissional em saúde ser voltada para o desenvolvimento da autonomia dos sujeitos, concentrada na crítica à educação bancária e na proposição de uma educação libertadora, voltada para a humanização. Isso decorre de um processo educativo e formativo que leva em conta a reflexão crítica como elo entre o indivíduo e o mundo e que haja o incentivo às potencialidades de autonomia do ser humano, garantindo a aplicação de técnicas com a arte do ser e do relacionar-se com o humano (Rosito; Loterio, 2012).

Neste sentido, a aprendizagem significativa representa o mais influente modelo adotado no processo de educação, no qual o aluno passa a ser o principal protagonista na construção de seu conhecimento. A aprendizagem passa a ser desenvolvida a partir de vivências significativas e conhecimentos prévios do aluno, apoiada nas descobertas e não no oferecimento de conteúdos e conceitos em sua forma fechada (Cyrino; Toralles-Pereira, 2004).

As metodologias ativas favorecem a motivação autônoma ao proporcionar ao aluno a percepção de ser a origem da própria ação, despertar a curiosidade e estimular o engajamento no processo de aprendizagem. Ao professor implica a promoção da autonomia dos alunos, necessitando nutrir os interesses pessoais, oferecer razões racionais para o estudo e o aprofundamento de determinados conteúdos, utilizar linguagem informacional e não controladora, acompanhar o ritmo de aprendizagem e ser receptivo às expressões de sentimentos negativos (Berbel, 2011).

Nesse contexto de mudança, a avaliação do aprendizado também requer a aplicação de métodos específicos, que gerem informações suficientes para a tomada de decisões inerentes ao processo 
de aprendizado e à localização do aluno quanto ao seu desempenho, estabelecendo de forma precisa o conjunto de habilidades que devem ser desenvolvidas (Troncon, 1996). Com a adoção de metodologias que coloquem o estudante como sujeito do processo de aprendizagem, a avaliação precisa deixar de ser um mero espaço para o exercício de poder ou um instrumento de punição adotado pelos professores (Gomes e outros, 2010).

Assim, no desenvolvimento do processo educacional, a avaliação do estudante deve ser efetuada em diferentes momentos e com distintas finalidades. A avaliação localizatória é aplicada com o objetivo de obter informações no início do processo educacional, para verificar o grau de domínio preliminar para a construção dos conhecimentos e habilidades do processo. A avaliação formativa é realizada periodicamente ao longo do processo educacional, com o intuito de obter dados sobre o progresso na construção do conhecimento por parte do estudante. Neste tipo de avaliação, o "feedback" imediato ao estudante é uma importante característica. Já a avaliação somativa ou terminal é a realizada no final do processo educacional, objetivando a verificação do grau atingido e com o propósito de aprovação ou reprovação do estudante (Troncon, 1996).

A escolha dos métodos de avaliação deve estar apoiada, inicialmente, no que se quer avaliar e por qual motivo, de modo que a avaliação de uma variada gama de habilidades, ou da resultante competência, requer a utilização de diferentes ferramentas e técnicas que, conjuntamente, poderão gerar o parecer final (Troncon, 1996). Ainda, outros aspectos que devem reger a escolha são a ligação do instrumento com a prática profissional, a complexidade das tarefas, as respostas esperadas, o tempo requerido na aplicação e na correção, a validade e a confiabilidade dos resultados obtidos (Lima, 2004).

Godoy (1995) salienta a importância do feedback que deve ser dado ao aluno, a partir de um processo de julgamento que envolve o conhecimento do padrão ou objetivo a ser atingido, a habilidade para estabelecer múltiplos critérios comparativos e o desenvolvimento de caminhos que reduzam a discrepância entre o que é produzido pelo aluno e o que foi proposto. Desta forma, o aluno recebe informações contínuas a respeito da qualidade do seu desempenho, que não fica reduzido a um número ou conceito.

O portfólio representa uma interessante alternativa para o desenvolvimento e avaliação de atividades nos cenários de prática profissional, instigando a reflexão e a articulação de conhecimentos 
Rigo, Ghisleni, Ely, Freitas, Bratti, Sehnem, Adami e Senna, 2016 - Tecnologia Educacional

teóricos aplicados no processo de trabalho. Através dessa ferramenta, o estudante reúne anotações, resumos, relatórios, esquemas, reflexões e outras diversas produções, para, posteriormente, determinar o que é mais significativo segundo suas experiências, o que evidencia seu avanço ou sua persistência em dificuldades não solucionadas. Nos atos de criar, criticar, contextualizar e questionar o conhecimento, o aluno passa a ser o protagonista de sua aprendizagem, desenvolvendo características fundamentais para a futura atividade profissional (Rangel, 2003).

Os critérios de avaliação deste instrumento podem ter como base a vivência adquirida e a capacidade de reflexão e agregação de conhecimento, através de relatos, propostas, fundamentação teórica e capacidade de escrita e síntese. A construção de portfólio aprimora o pensamento crítico e desenvolve habilidades como análise, síntese, expressão escrita, criatividade, busca autônoma do conhecimento e resolução de problemas complexos, além de tornar o aluno ator também da própria avaliação inserida na perspectiva formativa, possibilitando-o refletir sobre sua aprendizagem e identificar os ganhos e as instabilidades de sua trajetória acadêmica (Gomes e outros, 2010). Esta ferramenta serve como estratégia de estímulo, uma vez que o aluno realiza a documentação, o registro e a estruturação do seu processo de aprendizagem através de pactuação entre o educador e o educando, o que promove um trabalho colaborativo na condução e na resolução de problemas (Cotta e outros, 2012).

Os portfólios configuraram-se como metodologia de ensino, aprendizagem e avaliação em um contexto prático e teórico, cujo propósito é promover o aprendizado através da reflexão e da atualização pautada em pesquisa. Portanto, este estudo teve como objetivo verificar as percepções dos alunos de um curso de graduação na área da saúde, em relação ao uso do portfólio como instrumento de aprendizagem e avaliação.

\section{PERCURSO METODOLÓGICO}

Este estudo quantitativo, de caráter transversal, foi aplicado em uma turma de estudantes da disciplina de Introdução à Cosmética do curso de graduação em Estética e Cosmética da UNIVATES, uma instituição particular de Ensino Superior localizada na cidade de Lajeado, Rio Grande do Sul. Os estudantes da turma aceitaram participar da pesquisa por meio da assinatura de um Termo de Consentimento Livre e Esclarecido. 
No período de março a julho de 2014, os estudantes desenvolveram portfólios como parte integrante do processo de ensino-aprendizagem. Inicialmente, os graduandos foram orientados quanto à metodologia a ser utilizada para a elaboração e postagem do portfólio no decorrer do semestre, sendo ressaltados os objetivos do uso de tal instrumento: promover a reflexão crítica, a pesquisa e a autonomia na busca de conhecimento. Ainda, os estudantes foram informados de que o instrumento também constituiria um dos métodos de avaliação de desempenho individual.

Após cada aula, os estudantes tinham o prazo de cinco dias para postar o portfólio. A professora avaliava de maneira formativa, conforme os objetivos propostos para cada aula, fornecendo semanalmente um feedback. Durante todo o semestre, após a leitura de cada portfólio, a professora elaborava um relatório individual de cada estudante, contendo informações sobre o desempenho demonstrado e crescimento em relação à aprendizagem.

No final do semestre, foi aplicado um questionário no intuito de obter informações quanto à percepção dos alunos sobre a importância do portfólio como uma nova metodologia de aprendizagem e avaliação aplicada e verificar os aspectos positivos e negativos relacionados à utilização do portfólio. O questionário foi composto por quatro questões objetivas ("Como você avalia a metodologia ativa (portfólio) como prática de ensino? Quais os pontos relevantes desta metodologia? Você acha que esta metodologia deve ser aplicada em outras disciplinas? Como você avalia seu desenvolvimento intelectual relacionado à pratica profissional com a aplicação do portfólio?") e uma de caráter discursiva ("No seu ponto de vista, quais foram os pontos positivos e negativos do portfólio?").

Os dados foram descritos através de frequência e foram analisados através do teste do quiquadrado de Pearson com nível de significância de $p \leq 0,05$, utilizando o software Statistical Package for Social Sciences (SPSS), versão 18.0.

\section{RESULTADOS}

Dentre os 34 estudantes que responderam ao questionário, 94\% avaliaram a metodologia de uso do portfólio como "boa" e "ótima". Entre os estudantes, cuja opinião foi de que o portfólio corresponde a uma metodologia "ótima", $80 \%$ citaram como ponto relevante o incentivo à pesquisa (Tabela 1). E, entre os que consideraram a metodologia "boa", 54,5\% relataram ser o incentivo à pesquisa o ponto relevante, $36,4 \%$ acharam ser a provocação da reflexão própria e, 
$9,1 \%$ acharam ambos os aspectos importantes. Entre os estudantes que acharam a metodologia "ruim", 50,0\% relataram que a reflexão própria é um ponto relevante e 50,0\% acharam que não há ponto relevante na metodologia $(p=0,003)$.

Nesta reflexão percebe-se que, mesmo os que acharam a metodologia ruim, $50 \%$ relataram como sendo relevante a autorreflexão sobre os temas estudados. Conforme respostas, a metodologia foi considerada ruim porque a sua realização ocupava muito tempo fora da sala de aula.

Quando questionados sobre a possibilidade de aplicação da metodologia em outras disciplinas, $100,0 \%$ dos alunos que classificaram a metodologia como "ótima" e 54,5\% dos que avaliaram a metodologia como "boa" responderam que a mesma deveria ser aplicada também em outras disciplinas. Todos os alunos que acharam a metodologia "ruim" responderam que esta não deveria ser aplicada em outras disciplinas $(p=0,006)$.

Em relação ao desenvolvimento intelectual relacionado à prática profissional, $100,0 \%$ dos que avaliaram a metodologia como "ótima" e 95,5\% dos que consideraram a metodologia "boa" relataram ter percebido melhora em seu desenvolvimento intelectual, enquanto que $100,0 \%$ dos que julgaram a metodologia "ruim" relataram que não houve melhora no desenvolvimento intelectual $(p=0,001)$.

$\mathrm{Na}$ questão discursiva, os estudantes apontaram aspectos positivos e negativos do portfólio. Dentre os acadêmicos que consideram a metodologia "ótima", 10\% citaram, como ponto positivo, o incentivo à pesquisa e ao estudo e, outros $10 \%$ citaram o aprendizado constante. Os demais não responderam a este questionamento. Quanto aos que classificaram a metodologia como "boa", 4,5\% citaram que o processo de elaboração do portfólio é desgastante, 13,6\% relataram que há aprendizado constante com esta metodologia, e 27,3\% relataram ser desgastante, porém com incentivo ao estudo e à pesquisa $(p=0,002)$.

Tabela 1. Avaliação da aplicação do portfólio pelos estudantes da disciplina de Introdução à Cosmética do curso de graduação em Estética e Cosmética da UNIVATES com aplicação do Teste do qui-quadrado $(p<0,005)$.

Como você avalia a metodologia ativa (portfólio) como prática de ensino-aprendizagem?

Perguntas aplicadas

Boa Ruim Total


Rigo, Ghisleni, Ely, Freitas, Bratti, Sehnem, Adami e Senna, 2016 - Tecnologia Educacional

\begin{tabular}{|c|c|c|c|c|c|}
\hline & $\%$ & $\%$ & $\%$ & $\mathrm{~N}(\%)$ & \\
\hline \multicolumn{6}{|l|}{ Pontos relevantes desta metodologia: } \\
\hline Incentivo à Reflexão & 20,0 & 36,4 & 50,0 & $11(100,0)$ & 0,003 \\
\hline Incentivo à pesquisa & 80,0 & 54,5 & 0,0 & $20(100,0)$ & \\
\hline Incentivo à Reflexão própria e à pesquisa & 0,0 & 9,1 & 0,0 & $2(100,0)$ & \\
\hline Nenhum ponto relevante & 0,0 & 0,0 & 50,0 & $1(100,0)$ & \\
\hline \multicolumn{6}{|l|}{ A metodologia deve ser aplicada em outras disciplinas: } \\
\hline Sim & 100,0 & 54,5 & 0,0 & $22(100,0)$ & 0,006 \\
\hline Não & 0,0 & 45,5 & 100,0 & $12(100,0)$ & \\
\hline \multicolumn{6}{|c|}{ Desenvolvimento intelectual pessoa relacionado à pratica profissional: } \\
\hline Houve melhora & 100,0 & 95,5 & 0,0 & $31(100,0)$ & 0,001 \\
\hline Não houve melhora & 0,0 & 4,5 & 100,0 & $3(100,0)$ & \\
\hline \multicolumn{6}{|l|}{ Aspectos positivos e negativos do portfólio } \\
\hline Desgastante & 0,0 & 4,5 & 100,0 & $3(100,0)$ & 0,002 \\
\hline Incentivo à pesquisa e ao estudo & 10,0 & 0,0 & 0,0 & $1(100,0)$ & \\
\hline $\begin{array}{l}\text { Desgastante, com incentivo ao estudo e à } \\
\text { pesquisa }\end{array}$ & 0,0 & 27,3 & 0,0 & $6(100,0)$ & \\
\hline Não responderam & 80,0 & 54,5 & 0,0 & $20(100,0)$ & \\
\hline TOTAL & $10(100,0)$ & $22(100,0)$ & $2(100,0)$ & & \\
\hline
\end{tabular}

\section{DISCUSSÃO}

Tradicionalmente, a formação dos profissionais da saúde tem sido delineada através de cursos superiores baseados em conhecimentos compartimentados e disciplinas estanques, com o processo de ensino-aprendizagem restrito à simples recepção e reprodução do conhecimento por parte do estudante. Desta forma, o aluno percorre seu caminho acadêmico condicionado à simples retenção e repetição de informações, não desenvolvendo adequadamente o senso crítico e reflexivo necessário para o pleno desenvolvimento profissional (Mitre e outros, 2008). 
Neste estudo, a análise das respostas dadas pelos estudantes mostra que foi predominante o reconhecimento de que a adoção do método de elaboração do portfólio promove o incentivo à pesquisa de forma autônoma, à reflexão e, consequentemente, o melhor desenvolvimento intelectual. Mesmo entre os alunos que consideraram a metodologia ruim, metade deles classificou como relevante a provocação da autorreflexão sobre os temas estudados. Estes mesmos alunos justificaram a má adaptação a esta metodologia em função da demanda de tempo requerida fora da sala de aula para o seu desenvolvimento. Acredita-se que realmente a pouca disponibilidade de tempo tenha sido uma facilidade de todos os estudantes, uma vez que a disciplina era ofertada à noite e que a maior parte do grupo trabalhava durante o dia, restando apenas os poucos horários nos quais não tinham aula à noite ou o final de semana para a elaboração do portfólio. Tal fato evidencia uma das dificuldades que acompanham o processo de transição no formato de ensino conservador para um formato renovado, guiado pela aprendizagem significativa. O costume dos estudantes em agir de forma passiva na construção de seu conhecimento, aliado à frequente necessidade de arcar com as despesas de seu curso superior, quando em instituições particulares, acaba por criar um perfil discente com baixa percepção a respeito da importância da proatividade, focado na simples recepção de conteúdos e ansioso pela finalização do curso, a fim de ingressar no mercado de trabalho.

Friedrich e outros (2010) salientam que, para haver sucesso na utilização de metodologias ativas, tais como o portfólio, é fundamental a existência da relação dialógica, além do enfrentamento do processo com disciplina e rigor. A ferramenta perde seu sentido se não houver real aceitação e participação do corpo docente e discente. Desta forma, acredita-se que a rejeição ao portfólio possa ser paulatinamente contornada através de pactuações firmadas entre professor e aluno, de modo a salientar a importância de o estudante reservar momentos de seu dia para o estudo autodirigido, mas levando em consideração as possibilidades de dedicação ao desenvolvimento deste.

O estudo de Cotta e outros (2012) apresentou os resultados da experiência de aplicação de portfólios coletivos entre estudantes do ensino superior também baseado nos currículos tradicionais. De acordo com o relato dos alunos, o uso do portfólio mobilizou o pensamento crítico-reflexivo, valorizou o trabalho em equipe e a construção independente do conhecimento, e exercitou a alteridade, a resiliência e a apropriação do conhecimento. Entretanto, alguns depoimentos revela- 
ram outros aspectos limitantes do método, como a inexperiência anterior com a ferramenta, a dificuldade em desenvolver o trabalho em equipe e a repressão da capacidade de criação.

Outro estudo, realizado por Cotta, Da Costa e Mendonça (2013), analisou os resultados da experiência da construção coletiva de portfólios como método de ensino-aprendizagem em uma disciplina dos cursos de Enfermagem e Nutrição de uma universidade pública. Os autores verificaram que o portfólio constituiu uma ferramenta baseada no feedback, geradora de opiniões, dúvidas, dificuldades e vivências. Ele também facilitou o processo de reconstrução do conhecimento por parte dos discentes, sendo capaz de fornecer subsídios para a avaliação formativa destes.

A utilização do portfólio como instrumento inovador de ensino também foi avaliada em cursos de Odontologia. Na pesquisa de Frota e outros (2011) verificou-se que este foi bem aceito pela comunidade acadêmica, proporcionando o momento de feedback do professor e maior segurança e confiança por parte dos estudantes para a aplicação de mudanças necessárias no desenvolvimento do material produzido. Foi unânime entre os estudantes entrevistados que esta metodologia facilitou o processo de aprendizagem e estimulou a autonomia, a interação, a criatividade e a iniciativa de pesquisa. Maciel e outros (2014) apresentaram a percepção dos acadêmicos do curso de Odontologia no transcorrer do terceiro, sexto e oitavo semestres, salientando que o portfólio é um bom método de avaliação, embora grande parte dos acadêmicos tenha relatado dificuldades no desenvolvimento de reflexões para elaboração do material, na conexão entre os aspectos práticos e teóricos e na comunicação escrita. Em relação à visão dos docentes, o estudo de Forte e outros (2012) encontrou o reconhecimento da importância do portfólio como mecanismo reflexivo para a formação profissional, mas ressaltou a ainda frágil comunicação escrita dos estudantes.

Segundo Rangel (2003), o foco da avaliação não deve ser o julgamento de quem são os melhores alunos, mas sim alimentar e reorientar o trajeto de aprendizagem do estudante. Alvarenga e Araújo (2006) ressaltam que a avaliação através do portfólio requer tempo, paciência e prática, porém quando feita cuidadosamente e relacionando-a aos objetivos pretendidos, torna-o uma verdadeira "ferramenta de ouro". Os autores apresentam em seu estudo, a importante colocação de Fraisier e Paulson (1992) de que a utilização do portfólio ressalta as capacidades do aluno, e não suas fragilidades, fazendo com que, mesmo os estudantes com dificuldades em determinados 
assuntos passem a escrever melhor e a demonstrar o desejo de compartilhar suas produções com os colegas.

A aceitação por parte dos discentes como dos docentes encontra lacunas que só o tempo e a constância do seu uso poderão conduzir à plena aceitação. Segundo o que foi apreciado, ainda é cedo para admitir o êxito da experiência sugerida, pois ainda é necessário percorrer algumas etapas para que o método seja inteiramente aceito. Este tem seus prós muito visíveis e sua aplicação nunca estará fora de cogitação. O uso do portfólio como método de ensino-aprendizagem ou avaliação pode ser uma ferramenta poderosa no acompanhamento do estudante em seu processo de aprendizagem. Através dele é possível avaliar a evolução, não apenas nos aspectos cognitivos, como também nos aspectos atitudinais e psicomotores. Com isso, o acompanhamento, no sentido de corrigir as distorções e direcionar o processo de aprendizagem para atender aos conhecimentos, habilidades e atitudes desejadas para o profissional que se pretende formar.

Porém, esse processo não é simples, pois carece de mudança de atitudes por parte de todos os atores envolvidos. Neste trabalho, organizado a partir de uma prática em um curso de graduação, foi possível verificar os acertos e as dificuldades que o método impõe, assim como, indagações que permanecem sem resposta. Entretanto, percebe-se a evolução do estudante, assim como a sua aprovação perante o uso da nova metodologia.

\section{CONSIDERAÇÕES FINAIS}

O presente estudo permitiu concluir que o portfólio constitui uma interessante ferramenta para o desenvolvimento da aprendizagem e da autonomia dos estudantes, mesmo em cursos superiores pautados no método tradicional de ensino, uma vez que obteve boa aceitação por parte dos alunos. Pontos importantes como a necessária disponibilidade de tempo para seu desenvolvimento foram levantados, salientando a importância do bom planejamento para sua execução e da adequada pactuação entre docente e discentes. Julga-se que, apesar de algumas dificuldades relatadas pelos alunos, que o portfólio apresenta aspectos positivos que as superam, o que justifica sua utilização no processo de ensino-aprendizagem nos cursos de graduação, tanto da área da saúde como nos demais segmentos profissionais. 


\section{REFERÊNCIAS}

ALVARENGA, Georfravia Montoza; ARAúJO, Zilda Rossi. Portfólios: conceitos básicos e indicação para utilização. Estudos em Avaliação Educacional. Fundação Carlos Chagas, São Paulo, vol. 17, n. 33, p. 137-148, 2006.

BERBEL, Neusi Aparecida Navas. As Metodologias Ativas e a promoção da autonomia de estudantes. Semina: Ciências Sociais e Humanas, Londrina, vol. 32, n. 1, p. 25-40, 2011.

COTTA, Rosângela Minardi Mitri; DA COSTA, Glauce Dias; MENDONÇA, Érica Toledo. Portfólio reflexivo: uma proposta de ensino e aprendizagem orientada por competências. Ciência \& Saúde Coletiva, Rio de Janeiro, vol. 18, n. 6, p. 1847-1856, 2013.

COTTA, Rosângela Minardi Mitri; DA SILVA, Luciana Saraiva; LOPES, Lílian Lelis; GOMES, Karine de Oliveira; COTTA, Fernanda Mitre; LUGARINHO, Regina; MITRE, Sandra Minardi. Construção de portfólios coletivos em currículos tradicionais: uma proposta inovadora de ensino-aprendizagem. Ciência \& Saúde Coletiva, Rio de Janeiro, vol. 17, n. 3, p. 787-796, 2012.

CYRINO, Eliana Goldfarb; TORALLES-PEREIRA, Maria Lúcia. Trabalhando com estratégias de ensino-aprendizagem por descoberta na área da saúde: a Problematização e a Aprendizagem Baseada em Problemas. Cadernos de Saúde Pública, Rio de Janeiro, vol. 20, n. 3, p. 780-88, 2004.

FORTE, Franklin Delano Soares; VIEIRA, Liza Barreto; PESSOA, Talitha Rodrigues Ribeiro Fernandes; FREITAS, Claudia Helena Soares Morais; FERREIRA, Maria de Lourdes da Silva Marques. Portfólio: desafio de portar mais que folhas: a visão do docente de Odontologia. Revista Brasileira de Educação Médica, Rio de Janeiro, vol. 36, n. 1, p. 25 -32, 2012.

FRAZIER, Darlene M.; PAULSON, F. Leon. How portfolios motivate reluctant writers. Educational Leadership, Alexandria, vol. 49, n. 8, p. 62-65, 1992.

FRIEDRICH, Denise Barbosa de Castro; GONÇALVES, Ângela Maria Corrêa; DE SÁ, Tatiana Santos; SANGLARD, Leticia Ribeiro; DUQUE, Débora Ribeiro; DE OLIVEIRA, Gabriela Mota Antunes. O portfólio como avaliação: análise de sua utilização na graduação de enfermagem. Revista Latino-Americana de Enfermagem, Ribeirão Preto, vol. 18, n. 6, 2010.

FROTA, Myrna Maria Arcanjo; DE MENEZES, Léa Maria Bezerra; ALENCAR, Carlos Henrique; JORGE, Lidiane da Silva; DE ALMEIDA, Maria Eneide Leitão. O portfólio como estratégia facilitadora do processo de ensino-aprendizagem para a formação em Odontologia. Adequação de metodologias de ensino utilizando o ambiente virtual de aprendizagem. Revista da ABENO, Brasília, vol. 11, n. 1, p. 23-28, 2011.

GODOY, Arilda Schmidt. Avaliação da Aprendizagem no Ensino Superior: Estado da Arte. Didática, São Paulo, vol. 30, 1995.

GOMES, Andréia Patrícia; ARCURI, Mariana Beatriz; CRISTEL, Etelka Czako; RIBEIRO, Regina Meireles; SOUZA, Luciana M. Borges da Matta; SIQUEIRA-BATISTA, Rodrigo. Avaliação no Ensino Médico: o papel do portfólio nos currículos baseados em metodologias ativas. Revista Brasileira de Educação Médica, Rio de Janeiro, vol. 34, n. 3, p. 390-96, 2010.

LIMA, Valéria Vernaschi. Avaliação de competência nos cursos médicos. In: MARINS, João José Neves; REGO, Sérgio; LAMPERT, Jadete Barbosa; DE ARAÚJO, José Guido Correa (Orgs.). Educação Médica em transformação: instrumentos para a construção de novas realidades. São Paulo: Hucitec, 2004. p. 123-143.

MACIEL, Jacques Antonio Cavalcante; NORTE, Antônia Edênia Oliveira; FEITOSA, Sthefane Gomes; MOREIRA, Thiago Pelúcio; DE FARIAS, Mariana Ramalho; TEIXEIRA, Ana Karine Macedo. Percepção dos acadêmicos do curso de Odontologia sobre o uso do portfólio como método avaliativo. Revista Eletrônica Gestão \& Saúde, Brasília, vol. 5, n. 2, p. 279-289, 2014. 
MITRE, Sandra Minardi; SIQUEIRA-BATISTA, Rodrigo; GIRARDI-DE-MENDONÇA, José Márcio; DE MORAIS-PINTO, Neila Maria; MEIRELLES, Cynthia de Almeida Brandão; PINTO-PORTO, Cláudia; MOREIRA, Tânia; HOFFMANN, Leandro Marcial Amaral. Metodologias ativas de ensino-aprendizagem na formação profissional em saúde: debates atuais. Ciência \& Saúde Coletiva, Rio de Janeiro, vol. 13, p. 2133-2144, 2008.

RANGEL, Jurema Nogueira Mendes. O portfólio e a avaliação no ensino superior. Estudos em Avaliação Educacional, São Paulo, n. 28, p. 145-169, 2003.

ROSITO, Margaréte May Berkenbrok; LOTERIO, Marlene Goya. Formação do profissional em saúde: uma recusa ao esvaziamento de essência do cuidado humano. Educação e Realidade, vol. 37, n. 1, p. 125-142, 2012.

TRONCON, Luiz Ernesto de Almeida. Avaliação do estudante de medicina. Medicina, Ribeirão Preto, vol. 29, p. 429439, 1996 